\title{
NEONATAL OUTCOME IN ANEMIC MOTHERS: A PROSPECTIVE STUDY
}

Nisha Shah1, Chintan Upadhyay ${ }^{2}$, Ravi Sahota ${ }^{3}$

\section{HOW TO CITE THIS ARTICLE:}

Nisha Shah, Chintan Upadhyay, Ravi Sahota. "Neonatal outcome in anemic mothers: a prospective study". Jo urnal of Evolution of Medical and Dental Sciences 2013; Vol. 2, Issue 43, Octo ber 28; Page: 8355-8359.

BACKGROUND: Sepsis is the commonest cause of neonatal mortality .It is responsible for 30-50\% of neonatal deaths in developing countries. Anemia during pregnancy is highly prevalent in India. Anemia in pregnancy has adverse effects on maternal and fetal health. Obstetrical complications like low birth weight babies, IUGR, increased rate of preterm deliveries \& increased perinatal mortality are known. OBJECTIVES: Primary: To find relation between maternal anemia and proven neonatal sepsis. Secondary: To find long term morbidity and mortality of babies born to anemic mother. METHODS: The study was carried out in the Department of Pediatrics and Obstetrics and Gynaecology, Dr. B. R. Ambedkar Medical College and Hospital, Bangalore for a period of two years. A prospective randomized study conducted on 200 pregnant women who were found to be anaemic. All subjects were analyzed in full details and hemoglobin estimation done during $1^{\text {st }}$ visit, at $30^{\text {th }}$ week and $36^{\text {th }}$ week of gestation. Blood cultures were done in all the babies admitted to NICU for various reasons. RESULTS: The incidence of mild anaemia $29.5 \%$, moderate anemia $53 \%$ and $17.5 \%$ severe anaemia was noted in mothers. Out of total 200, 194 were liveborn and met the inclusion criteria, 20\% were preterm, 28\% IUGR, 51 babies(25\%) required NICU admission due to various reasons out of which 9\% developed proven sepsis. CONCLUSION: Anaemia in pregnancy continues to be a major problem in developing countries with maternal and fetal complications and neonatal sepsis was found to be indirectly associated with maternal anaemia.

KEYWORDS: Neonatal Sepsis, Maternal Anaemia ,Perinatal outcome

INTRODUCTION: Anaemia is medical problem that is frequently diagnosed and treated. The thought of a growing foetus in the mother's womb, indeed is nature's way of expressing the attributes of motherhood. ${ }^{1}$

Women of child bearing age, pregnant women, preterm and low birth weight infants, older infants and toddlers and teenage girls are at greatest risk of developing iron deficiency anaemia. Children with iron deficiency are at high risk of long term impairment in mental and motor development, lack of concentration, short attention span, easy distractibility, increased susceptibility to infection and abnormal appetite (pica). ${ }^{2}$

Some of the adverse effects of anaemia on the fetus were observed like fetal growth restriction (FGR), Preterm birth and Intrauterine fetal death s due to severe placental insufficiency. The incidence of still birth and preterm births have been found to decrease if iron therapy has been administered before 30 weeks of gestation.

Long term effects: Studies have shown that severe anaemia in the mother may result in behavioral abnormalities in children and reduced cognitive skills and impaired schooling later. This is said to be due to deficiency of chemical mediators in the fetal brain as a result of maternal iron deficiency.

AIMS AND OBJECTIVES: Primary: To find relation between maternal anaemia and proven neonatal 
complications. Secondary: To find long term morbidity and mortality of babies born to anaemic mothers.

METHODS: The study was carried out in the Department of Pediatrics and Obstetrics and Gynaecology, Dr. B. R. Ambedkar Medical College and Hospital, Bangalore for a period of two years. A prospective randomized study conducted on 200 pregnant women who were found to be anaemic. All subjects were analyzed in full details and hemoglobin estimation done during $1^{\text {st }}$ visit, at $30^{\text {th }}$ week and $36^{\text {th }}$ week of gestation. Blood cultures were done in all the babies admitted to NICU for various reasons.

\section{Results:}

Table 1: Table showing severity of anemia

\begin{tabular}{|c|c|c|}
\hline \multicolumn{3}{|c|}{ Severity of anaemia } \\
\hline Mild & Moderate & Severe \\
$(n=59)$ & $(n=106)$ & $(n=35)$ \\
\hline
\end{tabular}

There were 59 cases of mild anaemia, 106 and 35 were moderate and severe anaemia in the mother.

\begin{tabular}{|c|c|c|c|c|}
\hline & \multicolumn{3}{|c|}{ Severity of anaemia } & \multirow[b]{2}{*}{ p value } \\
\hline & $\begin{array}{c}\text { Mild } \\
(n=59)\end{array}$ & $\begin{array}{c}\text { Moderate } \\
(n=106)\end{array}$ & $\begin{array}{l}\text { Severe } \\
(n=35)\end{array}$ & \\
\hline \multicolumn{5}{|c|}{ Booked /Unbooked } \\
\hline Booked & 37 & 60 & 9 & \multirow{3}{*}{$0.009^{* *}$} \\
\hline Unbooked & 15 & 28 & 16 & \\
\hline Referred & 7 & 18 & 10 & \\
\hline $\begin{array}{r}\text { Table 2: } \\
\text { B }\end{array}$ & $\begin{array}{l}\text { able sho } \\
\text { B/R wit }\end{array}$ & $\begin{array}{l}\text { ving comr } \\
\text { severity }\end{array}$ & $\begin{array}{l}\text { ison bet } \\
\text { naemia }\end{array}$ & ween \\
\hline
\end{tabular}

A severity of anaemia was more common in unbooked and referred cases. p value 0.009 which is significant. 


\begin{tabular}{|c|c|c|c|c|}
\hline & \multicolumn{3}{|c|}{ Booked/ Unbooked/ Referred } & \multirow[b]{2}{*}{$\mathrm{p}$ value } \\
\hline & $\begin{array}{l}\text { Booked } \\
(\mathrm{n}=106)\end{array}$ & $\begin{array}{c}\text { Unbooked } \\
(\mathrm{n}=59)\end{array}$ & $\begin{array}{l}\text { Referred } \\
(n=35)\end{array}$ & \\
\hline \multicolumn{5}{|c|}{ Fetal outcome } \\
\hline $\mathrm{PT} / \mathrm{FT}$ & $(0 \%)$ & $(0 \%)$ & $(0 \%)$ & \multirow{3}{*}{$<0.001^{* *}$} \\
\hline - $\mathrm{PT}$ & $10(9.4 \%)$ & $16(27.1 \%)$ & $14(40 \%)$ & \\
\hline - $\mathrm{FT}$ & $96(90.6 \%)$ & $43(72.9 \%)$ & $21(60 \%)$ & \\
\hline \multicolumn{5}{|c|}{ IUGR } \\
\hline - No & $89(84 \%)$ & $37(62.7 \%)$ & $19(54.3 \%)$ & \multirow{2}{*}{$<0.001^{* *}$} \\
\hline - Yes & $17(16 \%)$ & $22(37.3 \%)$ & $17(48.6 \%)$ & \\
\hline \multicolumn{5}{|c|}{ NICU } \\
\hline - No & $88(83 \%)$ & $39(66.1 \%)$ & $22(62.9 \%)$ & \multirow{2}{*}{$0.013^{*}$} \\
\hline - Yes & $18(17 \%)$ & $20(33.9 \%)$ & $13(37.1 \%)$ & \\
\hline \multicolumn{5}{|c|}{ IUD } \\
\hline - No & 105(99.1\%) & $58(98.3 \%)$ & $31(88.6 \%)$ & \multirow{2}{*}{$0.023^{*}$} \\
\hline - Yes & $1(0.9 \%)$ & $1(1.7 \%)$ & $4(11.4 \%)$ & \\
\hline
\end{tabular}

Table 3: Table showing comparison between fetal outcomes with B/UB/R cases

The incidence of preterm babies, IUGR, IUD and NICU admissions were more in unbooked and referred cases compared to booked cases.out of total 200, 194 were live born. and met the inclusion criteria, 20\% were preterm, 28\% IUGR, 51 babies(25 \%) required NICU admission due to various reasons out of which $9 \%$ developed proven sepsis.

DISCUSSION: In the present study 200 cases were studied. The present study aimed at fetal outcome of anaemic mother.

The various parameters of the subjects were studied, analyzed and evaluated with the standard literature reading available.

In present study, $29.5 \%$ mild, $53 \%$ moderate and $17.5 \%$ were severely anaemic.

In present study $53 \%$ of women were booked cases. $29.5 \%$ and $17.5 \%$ were unbooked and referred cases respectively.

High incidence of adverse fetal outcome in the form of preterm (20\%), IUGR (28\%), NICU admission (25.5\%) and IUD (3\%) seen in present study. These were comparable with the observation of Awasthi A et $\mathrm{al}^{3}$ PT (9.5\%), IUGR (37.5\%) and IUD (8\%) and also comparable with Rangnekar et al6 PT (73\%), IUGR (4\%) and IUD (16\%). 
In the present study, incidence of preterm deliveries in unbooked cases $(27.1 \%)$ and referred cases (40\%) were high compared with booked cases (9.4\%). High incidence of IUGR was seen in unbooked (37.3\%) and referred (48.6\%) cases compared with booked cases (16\%). Out of 51 cases of NICU admission, 9\% cases were developed neonatal sepsis.

Among those unbooked (33.9\%) and referred (37.1\%) required more NICU admission compared to booked (17\%) cases due to severe anaemia. IUD was seen more in referred $(11.4 \%)$ cases with severe anaemia and associated risk factors were severe pre-eclampsia, GDM and PROM. These all outcome were statistically significant.

Incidence of low birth weight babies in the present study was $46.3 \%$ which was comparable with $66 \%$ observed by Rangnekar et al ${ }^{4}$

Incidence of low birth weight babies in the present study was $46.3 \%$ which was comparable with $66 \%$ observed by Rangnekar et al 6 and $69.1 \%$ by Khalida $\mathrm{H}$ et al. ${ }^{5}$

One of the recent study done in muscat in 2012 by Judith Angelitta and all sug gests that maternal age, parity and late prenatal visit were independently associated with maternal anaemia, low birth weight and preterm birth. ${ }^{6}$

Cochrane review 2009 shows that Microcytic hypochromic anaemia resulting from iron deficiency is the most frequent form of anaemia (76\%), followed by folate deficiency (20\%) and combined iron and folate deficiency $(20 \%){ }^{7}$

CONCLUSION: Anaemia is the commonest medical disorder in pregnancy which exists world over and is a very common problem in most of the developing countries. It is not only a medical problem, but is a major public health problem. Maternal and fetal complications and neonatal sepsis was found to be indirectly associated with maternal anaemia

Joint social and medical efforts are required for overall improvement of living status of women. To prevent neonatal complication in anemic women proper antenatal care is the basic requirement. Emphasis should be laid on prevention of anemia by active participation of governmental and nongovernmental organizations,IAP, local societies etc.

\section{REFERENCES:}

1. Purandare CA, Dalal RA and Purandare CB. Anaemia in Pregnancy. Page 1-59.

2. Commom issue in current concepts by Dr, Digant D. Shashtri, 2013Acedemic of pediatrics, Gujarat. P 85-89.

3. Awasthi A, Thakur R, Dave A, et al. Maternal and perinatal outcome in cases of Moderate and Severe anemia. J Obstet Gynaec of India. 2001 Dec; 51 (6): 62- 65.

4. Rangnekar AG and Darbari Rashmi. Fetal outcome in pregnancy anemia. J Obstet Gynaec of India. 1993 April; 43 (2): 172-176..

5. Khalida H, Shah GN, Farooq F. Some obstetric and fetal correlations in association with anemia in pregnancy. Indian Journal Maternal and Child health. 1997 April-June; 8(2): 48-50.

6. Journal of South Asian Federation of Obstetrics and Gynecology, January-April 2012;4(1):64-70

7. Pena-Rosas JP, Viteri FE. Effects and safety of preventive oral iron or iron and folic acid supplementation for women during pregnancy. Cochrane Database Systemic Review 2009;4:CD004736. 


\section{AUTHORS:}

1. Nisha Shah

2. Chintan Upadhyay

3. Ravi Sahota

\section{PARTICULARS OF CONTRIBUTORS:}

1. Assistant Prof essor, Department of Pediatrics, U.N. Mehta Cardiac Institute, Ahmedabad.

2. Senior Resident, Department of Obst. \& Gynaecology, GMERS Medical College, Sola, Ahmedabad.

3. Junior Resident, Departm ent of Pediatrics, Dr. B.R. Ambedkar Medical College, Bangalore.

\section{NAME ADDRESS EMAIL ID OF THE} CORRESPONDING AUTHOR:

Dr. Nisha Shah,

"KAILAS", No. 345, Sector - 1,

Gandhinagar, Gujarat - 382010.

Email - drchintanupadhyay@yaho o.com

Date of Submission: 20/10/2013.

Date of Peer Review: 21/10/2013.

Date of Acceptance: 23/10/2013.

Date of Publishing: 24/10/2013 